\title{
Is there a link between the unusually wet autumns in southeastern Norway and sea-surface temperature anomalies?
}

\author{
Rasmus E. Benestad*, Arne Melsom \\ The Norwegian Meteorological Institute, PO Box 43, 0313 Oslo, Norway
}

\begin{abstract}
During November 2000, Bjørnholt (near Oslo, Norway) received $564 \mathrm{~mm}$ of rain, the highest ever recorded by far. The extreme rainfall over south-eastern Norway accompanied a persistent circulation pattern advecting moisture from the south, leaving no doubt as to the role of the prevailing winds. However, there may be additional factors affecting the total rainfall amount, and one candidate is sea-surface temperature (SST). There were unusually warm SST anomalies off the coast of Newfoundland, and one central question is: Did the North Atlantic SSTs play a role? An analysis of the historical record of November rainfall from Bjørnholt is presented in order to explore plausible connections with the SST anomalies in the North Atlantic Ocean. It is found that the November rainfall is influenced by the SST in addition to the sea-level pressure (SLP). The SST anomalies cannot account for all of the $564 \mathrm{~mm}$ of rain, but the SSTs can nevertheless explain as much of the rainfall during unusually wet November months in 2000 and 1970 as the SLP. The November rainfall record coincides with the warmest SST anomalies on record in parts of the North Atlantic, and it is speculated as to whether this incidence can be related to a warming trend.
\end{abstract}

KEY WORDS: Rainfall $\cdot$ Sea-surface temperature $\cdot$ Sea-level pressure $\cdot$ Regression analysis

\section{INTRODUCTION}

Autumn in the year 2000 will be remembered as a wet one in parts of northern Europe (Marsh 2001), as there was widespread flooding and the rain never seemed to cease. The unusually high amount of rainfall accompanied a persistent circulation pattern (Fig. 1a) advecting mild and moist air from the south, and the whole of south-eastern Scandinavia received extreme amounts of precipitation, whereas northern and western Norway were unusually dry for this time of the year (Fig. 1b). November brought record rainfall in Oslo (Norway), with $279 \mathrm{~mm}$ (382\% of the 1961-1990 November mean) recorded at the Norwegian Meteorological Institute (met.no) at Blindern, almost trivializing the old record of $180 \mathrm{~mm}$ (1970). The rainfall amounts recorded at nearby stations within Oslo's city limits were as follows: Rustasaga, $335 \mathrm{~mm}(403 \%)$; Nordstrand, $290 \mathrm{~mm}(408 \%)$; Maridalsoset, $327 \mathrm{~mm}$ (403\%); Bjørnholt, $564 \mathrm{~mm} \mathrm{(470 \% );} \mathrm{Smestad,} 280 \mathrm{~mm}$
(384\%); Tryvasshøgda, $411 \mathrm{~mm}(340 \%)$; and Sørkedalen, $448 \mathrm{~mm}(444 \%)$. Details on the distribution of daily rainfall amounts are given in Table 1. Extreme rainfall amounts were also recorded over a substantial part of south-eastern Scandinavia (Fig. 1c).

Since November 2000 rainfall is the highest value ever recorded, analysis of the likelihood of such occurrences must be based on an extrapolation of probabilities (Coles 1999). The return time for the November rainfall in Bjørnholt (a settlement located on the south end of the Bjørnsjøen lake $360 \mathrm{~m}$ above sea level (masl) in the Nordmarka forest and within Oslo's city limit) is estimated to be $\sim 600 \mathrm{yr}$, assuming a Gumbel distribution (Wilks 1995, von Storch \& Zwiers 1999) and that the rainfall data is stationary. However, this estimate is highly uncertain due to the assumption of a Gumbel distribution and only $118 \mathrm{yr}$ of observations. Nevertheless, November rainfall at Bjørnholt exceeding $564 \mathrm{~mm}$ is a rare event indeed. From Table 1, we note that the November 2000 statistics of daily precipitation reveal 

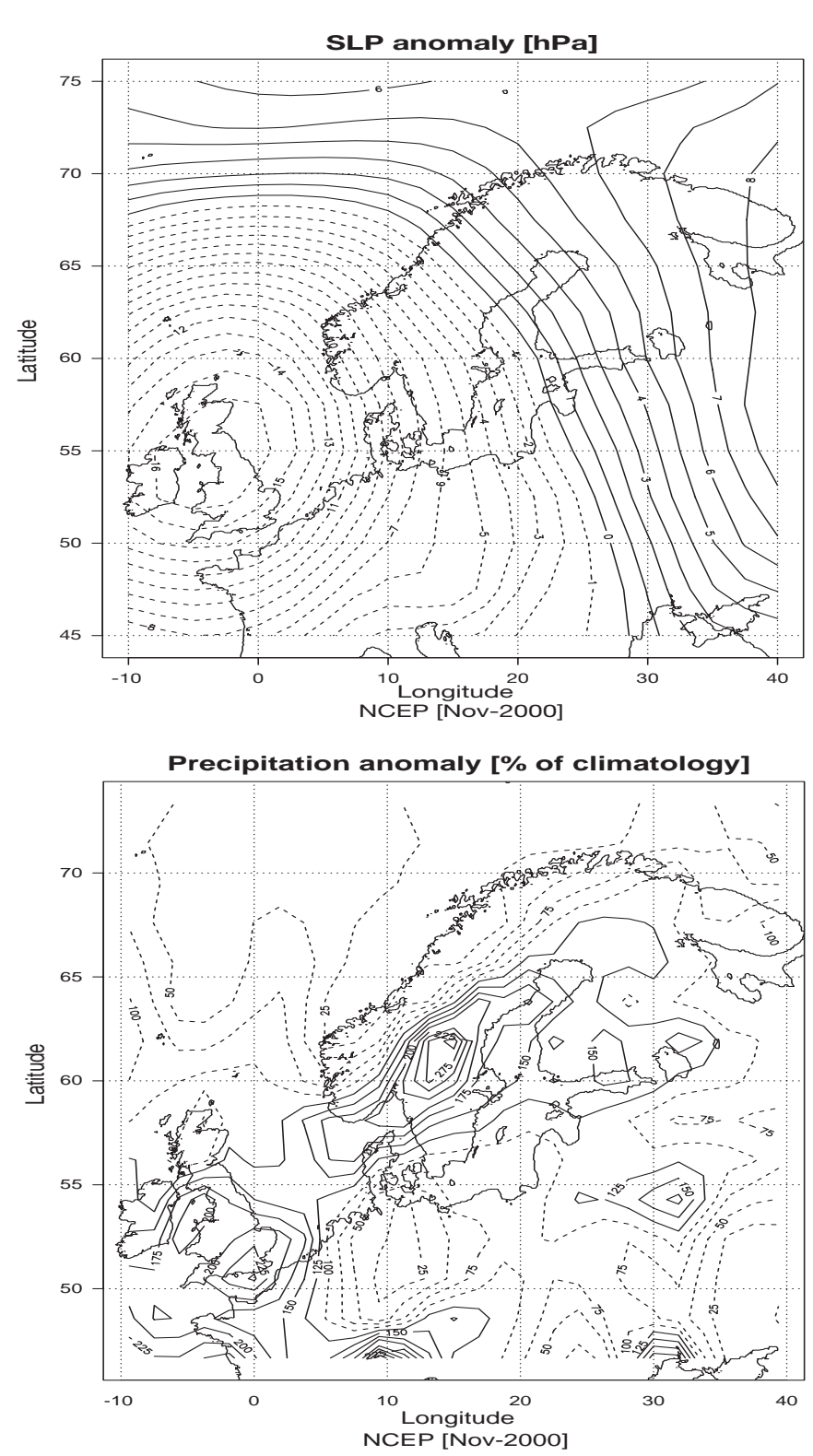

that the number of wet days was extreme. It rained on all but 2 days, which gives an indication of the persistence of the circulation pattern.

The question is then: Was this extreme rainfall event solely due to the persistent circulation pattern or were other factors ${ }^{1}$ also involved? In order to answer this question, one must look to the past rainfall measurements to identify underlying causes. Here, one plausible culprit is investigated: the North-Atlantic sea-surface temperature (SST). The link between SST and sea-level pressure (SLP) is also explored. It was established long ago that the atmospheric circulation influences the SST (Bjerknes 1959), but the atmospheric circulation also controls the geographical rainfall distribution (Busuioc et al. 2001, Hanssen-Bauer \& Førland 2000). The question is whether unusual SST

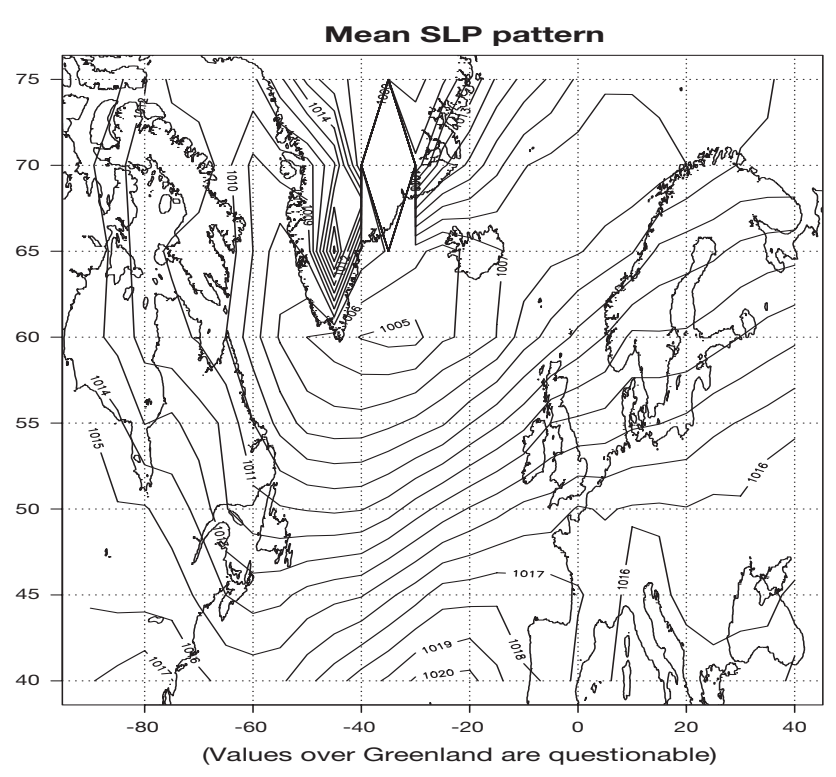

Fig. 1. (a) The prevailing SLP pattern for November 2000, (b) the 1900-2000 mean November SLP pattern, and (c) the November 2000 rainfall anomalies over northern Europe according to the NCEP reanalysis. The rainfall is expressed in terms of a percentage of the November mean, and the contour intervals are $1 \mathrm{hPa}$ in (a) and $25 \%$ in (b). Negative values in (a) are shown with dashed contours, whereas dashed contours in (b) indicate precipitation lower than normal. Note: The rainfall from the NCEP reanalysis shows the smoothed largescale structure, but does not capture the extreme values seen in the station records (e.g. Oslo-Blindern: observed $279 \mathrm{~mm}=$ $382 \%$, whereas the NCEP reanalysis only suggests values of the order of $100 \%$ )

anomalies (SSTAs) may affect the atmosphere in a reciprocal way, so that the rainfall is enhanced further. The connection between SSTAs and rainfall may be physically sound for several reasons: (1) the total rainfall is sensitive to the available moisture, and a high

\footnotetext{
${ }^{1}$ The continuity equation can be written as $\partial p / \partial t+\vec{u} \cdot \nabla p=$ source $-\operatorname{sink}$, where $p$ represents the humidity and $\vec{u}$ is the 3 -dimensional velocity. The source term is related to evaporation, which can be represented as a bulk-formula function of wind speed and the difference between the sea-surface temperature (SST) and the surface air temperature. The sink term involves precipitation. If the humidity is approximately constant, $\partial p / \partial t \approx 0$, then $\operatorname{sink}=$ source $-\vec{u} \cdot \nabla p$. Hence, important factors affecting the precipitation include local raingenerating mechanisms, moisture convergence (circulation pattern), and evaporation (SST)
} 
Table 1. 1961-1990 climatology of daily November rainfall amounts exceeding various threshold values for Bjørnholt (Columns 2-3), the 1900-1999 extremes (Columns 4-5), and the 2000 case (Column 6)

\begin{tabular}{|c|c|c|c|c|c|}
\hline \multirow{2}{*}{$\begin{array}{l}\text { Category } \\
(\mathrm{mm})\end{array}$} & \multicolumn{2}{|c|}{ 1961-1990 } & \multicolumn{2}{|c|}{ 1900-1999 } & \multirow[t]{2}{*}{2000} \\
\hline & Mean & $\mathrm{SD}$ & Min. & Max. & \\
\hline 0 & 14.0 & 4.4 & 4 & 25 & 2 \\
\hline$>10$ & 4.0 & 2.4 & 0 & 10 & 17 \\
\hline$>20$ & 1.5 & 1.4 & 0 & 6 & 11 \\
\hline$>30$ & 0.7 & 0.9 & 0 & 3 & 6 \\
\hline$>50$ & 0.1 & 0.4 & 0 & 1 & 3 \\
\hline
\end{tabular}

SST enhances the evaporation in addition to strong surface winds; (2) the SST may influence the circulation pattern; (3) high SSTs may provide an added source of energy for atmospheric cyclonic activity (Rodwell et al. 1999). The effect of SSTs on the atmosphere will depend on the atmospheric state, for instance, greater ocean-atmosphere heat exchange during situations with cool northerly wind anomalies than when mild southerly winds occur (Bjerknes 1959). However, some studies based on general circulation models (GCMs) suggest that the mid-latitude SSTAs have few, if any, effects on the atmospheric circulation (Frankignoul 1985, Lau 1996). Some model studies have even suggested that most of the low-frequency atmospheric variations are due to internal atmospheric dynamics (Lau 1985). Lag-correlation studies yield higher correlation estimates when the atmosphere leads the ocean (Frankignoul 1985). Johansson et al. (1998) conducted a study on the predictability of monthly mean temperatures in Europe based on empirical models and found little predictive information from the Atlantic Ocean SSTs.

But there are also some indications suggesting that the SSTAs have some influence on the atmosphere (Drevillion et al. 2001, Rîmbu et al. 2001). Colman \& Davey (1999) reported some skill in predicting summertime temperatures based on January-February North Atlantic SSTAs, implying a lagged atmospheric response to the ocean. Frankignoul (1985) observed that mid-latitude SSTAs have a weak but significant influence on the short-term climatic fluctuations. Sutton et al. (2000), Robertson et al. (2000), Rodwell et al. (1999), Selten et al. (1999) and Palmer \& Sun (1985), among others, have used atmospheric models to study the relationship between the North Atlantic SSTAs and atmospheric circulation, and their conclusion is that the former do affect the latter. The atmospheric response to diabatic heating such as SSTAs may include changes in the planetary wave propagation in addition to humidity changes, but the heating also depends on the dynamical response of the atmosphere
(Frankignoul 1985). Simulated atmospheric response tends to be model dependent, sensitive to the time scale, and may vary from study to study. It is possible that the GCMs have serious shortcomings due to uncertainties in the description of the relationship between SSTs and diabatic heating, preventing them from giving a true description of the actual relationships.

On longer time scales, there is further evidence pointing towards the ocean modifying the atmosphere (Timmermann et al. 1998, Kushnir \& Held 1996). Rodwell et al. (1999) and Higuchi et al. (1999) suggested that the phase of the North Atlantic Oscillation (NAO) is influenced by the North Atlantic SST on decadal time scales.

\section{DATA}

The monthly rainfall data for Bjørnholt was obtained from the Norwegian Meteorological Institute's (met.no) climatological database. The Oslo-Blindern (94 masl) record is not homogeneous, and values before 1937 have been reconstructed using neighbouring stations. The analysis for the 2 records gave qualitatively similar results, but only the Bjørnholt data, which has been homogenized and covers the period 1883-2001, will be discussed here.

In order to establish a link between large-scale anomalies over the North Atlantic Ocean and the autumn precipitation near Oslo, 101 yr long data records of SLP were constructed for the period 19002000 by combining the SLP from the University of East Anglia and NCEP reanalysis (Kalnay et al. 1996). The data were gridded using a optimal interpolation technique (Reynolds \& Smith 1994), and the construction, evaluation and data are described in Benestad (2000).

SSTs were based on COADS (Slutz et al. 1985), GISST2.2 (Parker et al. 1995, Kaplan et al. 1998), and the Reynolds \& Smith (1994) SSTs. The SST data were derived by Benestad using the same method as that used to find the $2 \mathrm{~m}$ temperature described in Benestad (2000). Moreover, the reconstruction of the SST data was done by projecting a combination of past observations from various sources onto corresponding eigen-patterns estimated from the Reynolds \& Smith (1994) SSTs. Since there are differences between the data from the various sources, the combination of the different sets is not a trivial task. The largest errors in the SSTs are estimated for the Labrador Sea and east of Greenland (not shown). There have been some studies which suggest that the North European weather is sensitive to the surface conditions in the Labrador Sea (Skeie \& Kvamstø 2000). Relatively large differences among the different SST data products, and hence 
large errors, were also found along the ice edge, so these SST products may not be ideal for studying the links between the Labrador Sea and climate anomalies associated with the storm tracks. Although the met. no SST reconstruction based on these different data sources is far from error-free, one may expect, from the reasonable agreement among the different sources in the well-sampled regions over substantial parts of the North Atlantic, that the reconstructed SST record (1900-2000) contains most of the climatic signals that can be related to climatic anomalies such as the wet spell in Oslo.

The robustness of the results was assessed by comparing the results with a similar analysis based on the HadISST1.1 product (www.cgd.ucar.edu/ asphilli/ DataCatalog/Data/hadisst.html) from the UK Meteorological Office (UKMO) instead of the met. no SSTs. The UKMO data consists of monthly mean SST and sea-ice analyses on a global scale from 1871 to 1999. Thus, the data do not cover the most recent extreme wet event of November 2000 and were therefore merely used to check the consistency of the historical SST-rainfall connection derived from the met. no reconstruction. It is important to note that the HadISST1.1 data set is based on many of the same observations as the met. no reconstruction; the 2 results are therefore not completely independent. Furthermore, these data are also susceptible to errors, particularly in the beginning of the record, when the observations were scarce. The SST reconstruction was compared to the Modular Ocean Data Analysis System (MODAS) SST product for the period 1993-2000, which is based on remotesensing data only (Fox et al. 2001). The comparison suggests that the reconstructed SSTs may be too smooth. More important is the comparison of the yearto-year changes of the November SSTAs, which is favorable for most of the common years but not for all. The mean November cloud cover in this domain is about $50 \%$ according to the NCEP reanalysis, which may introduce errors to the satellite product. Thus, none of these products is perfect.

The gridded November mean rainfall values shown in Fig. 1c were taken from the NCEP reanalysis obtained from the NOAA-CIRES Climate Diagnostic Center (CDC) in the USA. An alternative option was to use the ECMWF's analysis (EA) product. However, the EA only dates back to the late 1970s, and is not as suitable for the present purpose as the $53 \mathrm{yr}$ with NCEP reanalysis data. Furthermore, the NCEP reanalysis is much more easy to obtain for the science community at large, making it the preferred choice for this study.

In order to test the reconstructed data for a real climate signal, a canonical correlation analysis (CCA) was applied to the SST and SLP fields, extracting spatial patterns which are associated with one another (not shown). The patterns bear similarities to the NAO. The first canonical correlation coefficient is 0.83 for the 1900-2000 interval, which is indicative of a coupled signal.

\section{METHODS}

The SST and SLP fields were subject to an empirical orthogonal function (EOF) (Lorenz 1956, North et al. 1982, Benestad 1999) decomposition in order to reduce the data size and hence reduce the degrees of freedom. Using only the 20 leading principal components (PCs) from the EOF analysis makes the analysis easier and reduces the computational demands (accounting for $99.96 \%$ of the variance in the SST and $99.19 \%$ of the variance in the SLP). Furthermore, throwing away the higher-order EOFs removes much of the noise in the data. One disadvantage with this kind of 'filtering', however, is that weak signals may also be excluded.

The November rainfall data (rr) were not normally distributed, and the precipitation series was therefore normalized in 3 different ways: by taking $\log (r r), r r^{0.2}$ power, or $r r^{0.5}$-power transforms of the series. The analysis was repeated for these transforms, and the results were similar. We therefore henceforth focus on the original data.

In order to explore any association between the SST (SLP) and the rainfall over south-eastern Norway, 3 different lines of analysis were conducted: (1) $t$-tests of SST PCs coinciding with the times when there were wet autumns; (2) the spatial extent of prominent SSTAs; and (3) regressional analysis.

In approach (1), the 1900-2000 November months were classified in terms of dry, normal and wet months by 'binning' the data into 3 categories defined in terms of the mean value $(\mu)$ of $r r$ and the standard deviation $(s): r r_{\text {dry }}<\mu-0.42 s ; r r_{\text {wet }}>\mu+0.42 s$; and $r r_{\text {norm }}$ within $\pm 0.42 s$ of or equal to $\mu$. If the rainfall data are normally distributed about the mean value, then the chance that the rainfall amount falls into each category is $33 \%$. The actual fractions of cases in each category are given in Table 2, which shows that neither the original data nor most of the transformations give an equal distribution over categories. The observations tend to favour more dry cases, whereas the transformations give more wet events (the years which fall under category 'wet' are listed in Table 3). The distributions of $r r$ and $r r^{0.2}$ fall just outside the $95 \%$ confidence interval for normally distributed data estimated through Monte-Carlo simulations, whereas the $r r^{0.5}$ transformation gives a nearly equal distribution among the different categories.

Three sets of $t$-tests were conducted, all of which were applied to the PCs of the SSTs or SLPs grouped as wet, normal or dry autumns. In approach (2) the asym- 
Table 2. Fraction (in percent) of wet, normal and dry November months. The total number of cases is 101, and the numbers shown in bold are outside the $95 \%$ confidence interval if the data were normally distributed. The confidence levels corresponding to p-values of 0.025 and 0.975 are shown in italics and were computed using 10000 Monte-Carlo simulations

\begin{tabular}{|lccc|}
\hline Transform & Wet & Normal & Dry \\
\hline$r r$ & 32 & 27 & $\mathbf{4 1}$ \\
$\log (r r)$ & $\mathbf{4 2}$ & 25 & 33 \\
$r r^{0.2}$ & $\mathbf{4 1}$ & 26 & 33 \\
$r r^{0.5}$ & 36 & 31 & 34 \\
$\mathrm{p}=0.025$ & 28 & 25 & 29 \\
$\mathrm{p}=0.975$ & 40 & 41 & 40 \\
\hline
\end{tabular}

metry of the distribution of warm and cold pools in the North Atlantic Ocean were compared with the temporal variability of the original rainfall series, and the results were categorized and subjected to a bootstrap test. Finally, in approach (3) a stepwise regression was used to develop multiple linear empirical models describing the November rainfall in terms of the respective SST or SLP PCs.

\section{RESULTS}

Fig. 2 shows the results from the $t$-tests. In Fig. 2a, the $t$-test is applied to the respective populations of PC values corresponding to wet and dry November months for the $r r^{0.5}$ transformation. The 3rd, 4th, 6th and 10th SST modes are statistically significant at the $5 \%$ level, indicating that some of the EOFs are in fact associated with wet November months. The $t$-test results for normal and dry months (Fig. 2b) give some indications of a relationship between SST and rainfall that verges on being statistically significant at the $5 \%$ confidence level. A similar test for the populations of wet and normal months (not shown) point to statistically significant relationships with the SST modes, but these are not quite as strong as for the wet-dry differences. The $t$-tests were repeated using classifications based on $r r, \log (r r)$, and $r r^{0.2}$ respectively, which all, except the $t$-test between dry and normal November for the $\log (r r)$-based categorization (not shown), pointed to statistically significant differences (at the $5 \%$ confidence level) between the mode-3 weighting for the different classes. The fact that 1 mode qualifies as statistically significant in nearly all these tests suggests that the results are valid, and it is not just a coincidence, even though there is a good chance of finding 1 case which qualifies as 'statistically significant' out of 20 independent estimates (the problem of multiplicity; Wilks 1995).
Table 3. An overview of the wet November months at Bjørnholt over the period 1900-2000. The 1961-1990 normal value is $120 \mathrm{~mm}$. The second column lists the wet November months defined using the raw data (not transformed and not normally distributed), whereas columns 3 and 4 show the wet events when using the transformed for the categorisation according to $r r$ or the 2 transforms

\begin{tabular}{|c|c|c|c|c|}
\hline Year & $\begin{array}{l}\text { Original } \\
(\mathrm{mm})\end{array}$ & $\begin{array}{c}\log \\
(\log [\mathrm{mm}])\end{array}$ & $\begin{array}{c}r r^{0.2} \\
\left(\mathrm{~mm}^{0.2}\right)\end{array}$ & $\begin{array}{c}r r^{0.5} \\
\left(\mathrm{~mm}^{0.5}\right)\end{array}$ \\
\hline 2000 & 564.1 & 564.1 & 564.1 & 564.1 \\
\hline 1929 & 291.5 & 291.5 & 291.5 & 291.5 \\
\hline 1970 & 291.1 & 291.1 & 291.1 & 291.1 \\
\hline 1916 & 246.2 & 154.9 & 246.2 & 246.2 \\
\hline 1959 & 242.6 & 242.6 & 242.6 & 242.6 \\
\hline 1926 & 240.1 & 240.1 & 240.1 & 240.1 \\
\hline 1960 & 234.7 & 234.7 & 234.7 & 234.7 \\
\hline 1991 & 232.9 & 232.9 & 232.9 & 232.9 \\
\hline 1974 & 224.0 & 224.0 & 224.0 & 224.0 \\
\hline 1992 & 220.0 & 220.0 & 220.0 & 220.0 \\
\hline 1982 & 207.7 & 207.7 & 207.7 & 207.7 \\
\hline 1931 & 193.1 & 193.1 & 193.1 & 193.1 \\
\hline 1977 & 192.4 & 192.4 & 192.4 & 192.4 \\
\hline 1967 & 185.2 & 185.2 & 185.2 & 185.2 \\
\hline 1928 & 185.1 & 185.1 & 185.1 & 185.1 \\
\hline 1935 & 180.1 & 180.1 & 180.1 & 180.1 \\
\hline 1938 & 177.9 & 177.9 & 177.9 & 177.9 \\
\hline 1939 & 176.3 & 176.3 & 176.3 & 176.3 \\
\hline 1963 & 176.2 & 176.2 & 176.2 & 176.2 \\
\hline 1961 & 172.9 & 172.9 & 172.9 & 172.9 \\
\hline 1949 & 170.3 & 170.3 & 170.3 & 170.3 \\
\hline 1981 & 169.5 & 169.5 & 169.5 & 169.5 \\
\hline 1910 & 169.1 & 169.1 & 169.1 & 169.1 \\
\hline 1954 & 166.1 & 166.1 & 166.1 & 166.1 \\
\hline 1979 & 166.1 & 166.1 & 166.1 & 166.1 \\
\hline 1951 & 165.9 & 165.9 & 165.9 & 165.9 \\
\hline 1993 & 163.5 & 163.5 & 163.5 & 163.5 \\
\hline 1950 & 157.9 & 157.9 & 157.9 & 157.9 \\
\hline 1966 & 156.4 & 156.4 & 156.4 & 156.4 \\
\hline 1943 & 155.0 & 155.0 & 155.0 & 155.0 \\
\hline 1913 & 154.9 & 154.9 & 154.9 & 154.9 \\
\hline 1946 & 153.4 & 153.4 & 153.4 & 153.4 \\
\hline 1987 & 152.6 & 152.6 & 152.6 & 152.6 \\
\hline 1989 & & 140.9 & 140.9 & 140.9 \\
\hline 1905 & & 141.8 & 141.8 & 141.8 \\
\hline 1986 & & 141.4 & 141.4 & 141.4 \\
\hline 1923 & & 139.0 & 139.0 & \\
\hline 1940 & & 136.4 & 136.4 & \\
\hline 1930 & & 135.7 & 135.7 & \\
\hline 1907 & & 133.1 & 133.1 & \\
\hline 1976 & & 132.9 & & \\
\hline 1942 & & 131.8 & & \\
\hline Limit & 152.5 & 129.3 & 133.0 & 140 \\
\hline Cases & 33 & 42 & 40 & 36 \\
\hline
\end{tabular}

A composite reconstruction of the met. no SST difference corresponding to the 'wet' Novembers listed in Table 3 (Column 2) and corresponding 'dry' months is shown in Fig. 3a, indicating positive SSTAs off the Newfoundland coast. High November rainfall is also accompanied with a cold ocean surface west of the British Isles. The SST observations for November 2000 
show strong anomalies southeast of Labrador, the interior North Atlantic and along the Norwegian coast (Fig. 3b).

A comparison with the standard deviation of the November mean SST (1981-2000) shows that the amplitudes of the November 2000 SSTAs south-east of Labrador were a factor of 2 higher than the 1981-2000 standard deviation as well as the 1900-2000 standard deviation derived from the 1900-2000 met. no SST reconstruction (not shown). The November 2000 temperatures in this region were in fact the highest in the entire Reynolds SST record (1981-2000, Fig. 4a). The corresponding spatial mean temperatures derived from the 1900-2000 met. no SST analysis suggest that there is no evidence of past values being higher than in November 2000. Fig. 4b compares the time series of
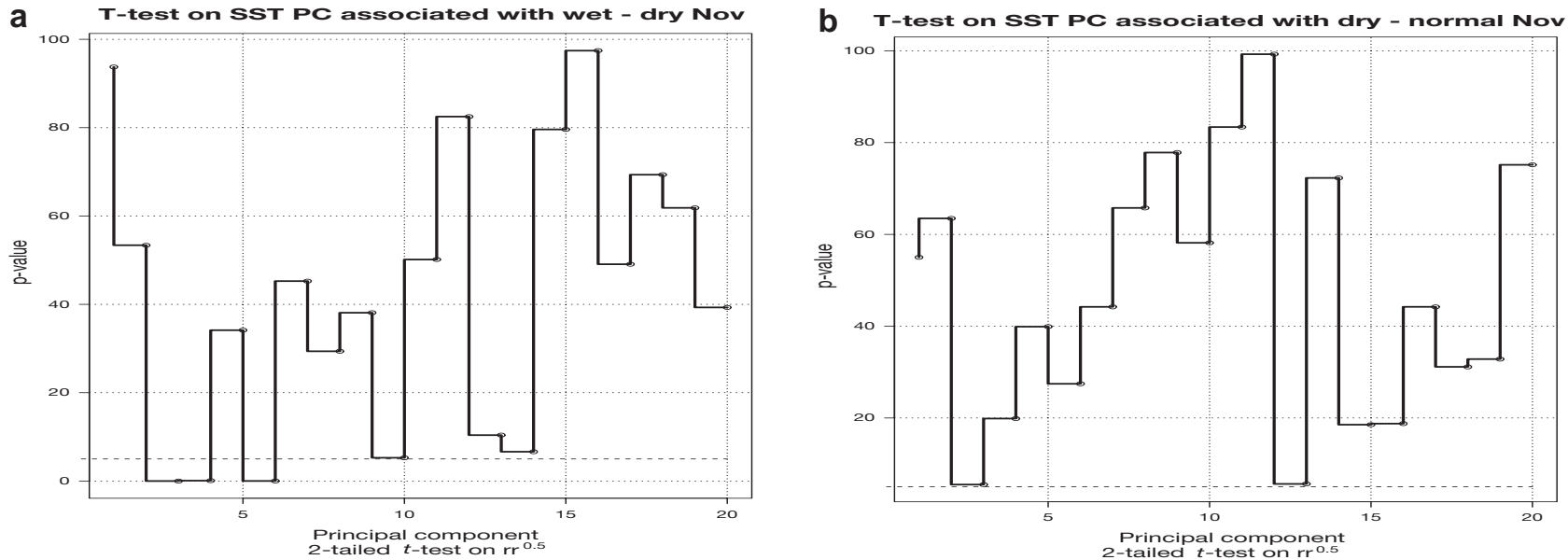

Fig. 2. Welch 2-sample $t$-test scores using SST for 2 populations of PC values corresponding to (a) wet and dry and (b) dry and normal Novembers. The dashed horizontal line marks the $5 \%$ confidence level
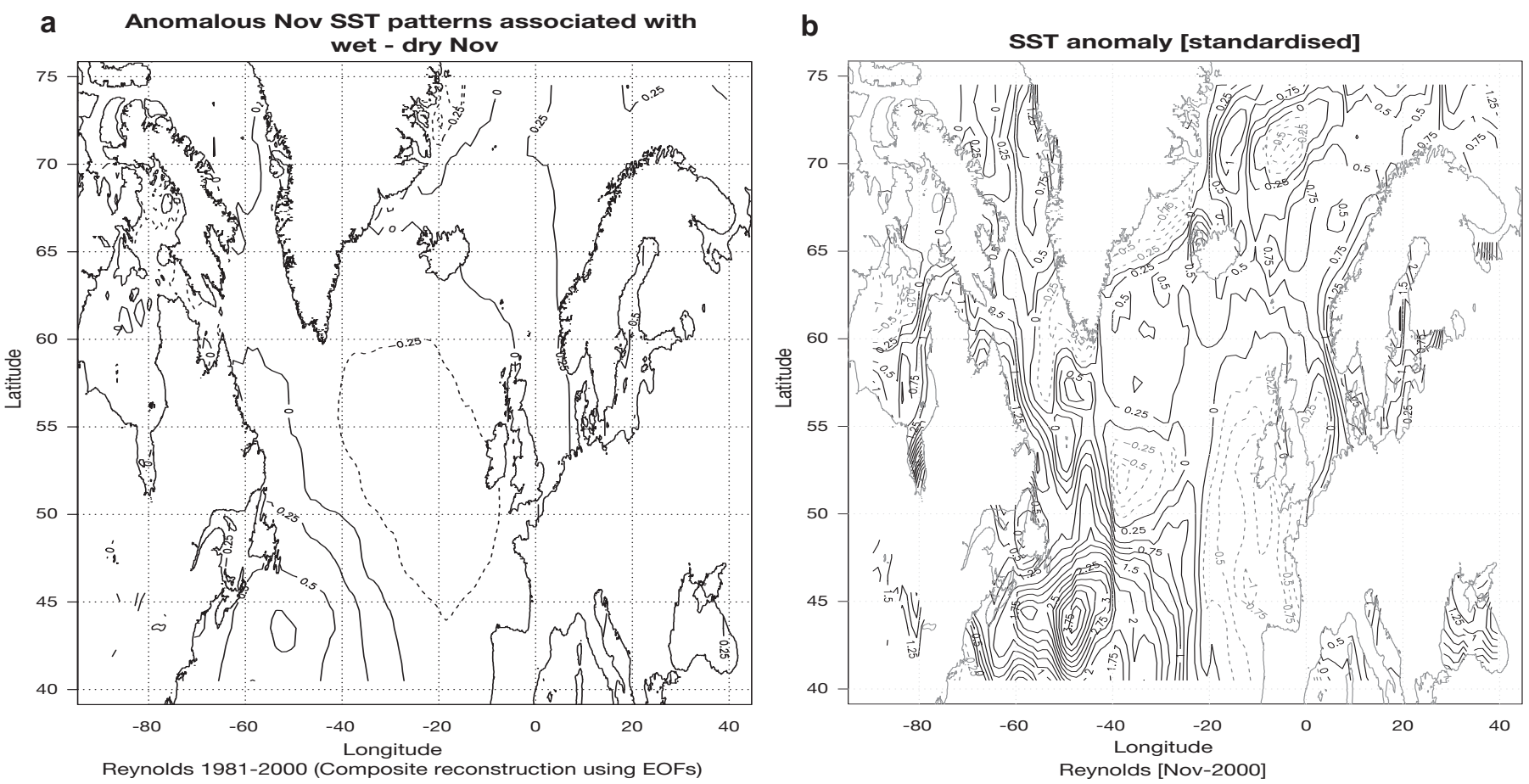

Fig. 3. (a) Composite difference between met. no SST anomaly pattern of all the 1900-2000 November months coinciding with high and low rainfall. (b) Reynolds \& Smith (1994) SST anomalies of November 2000. The contour intervals are $0.25^{\circ} \mathrm{C}$ 


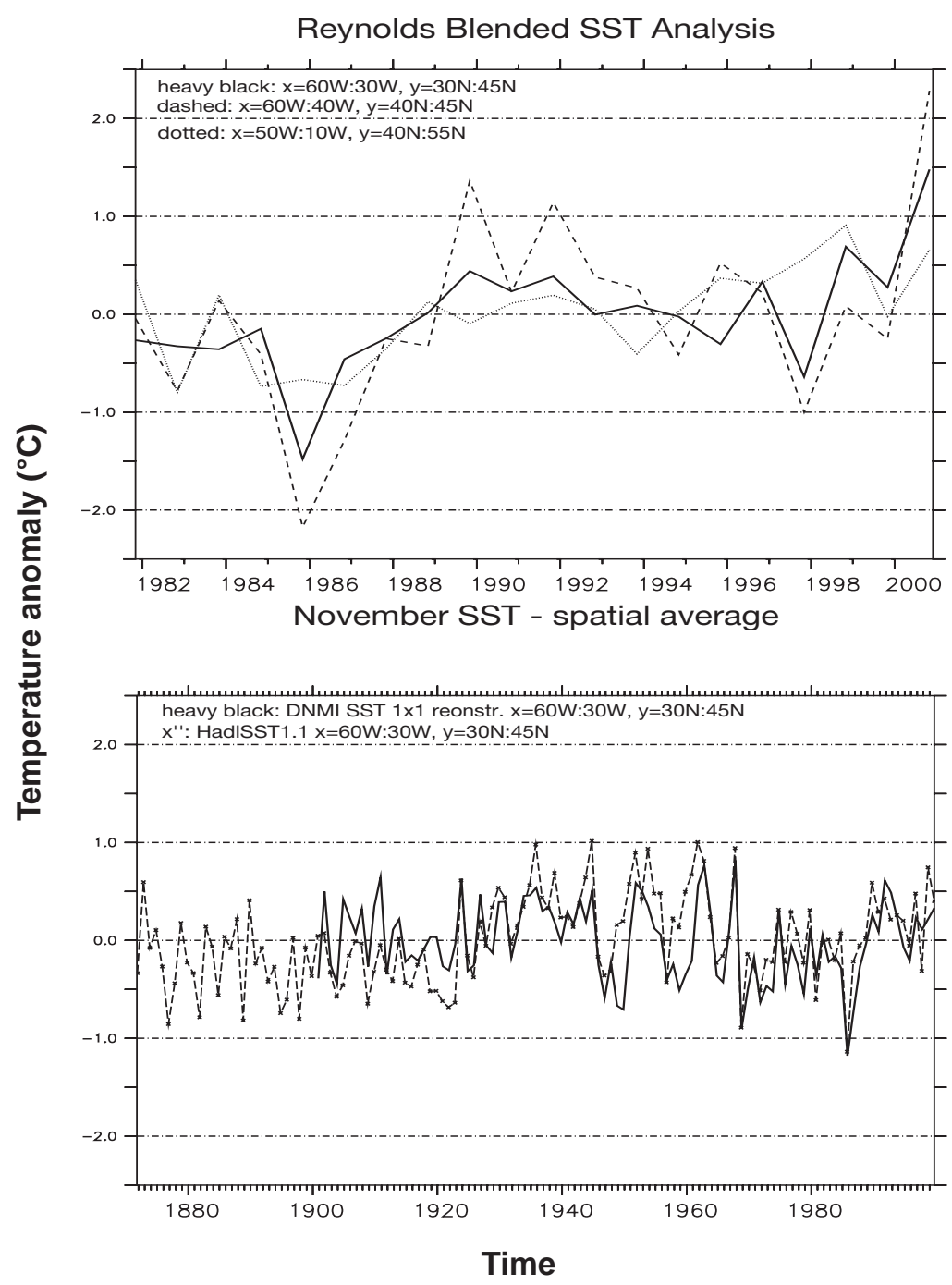

Fig. 4. Time series showing the evolution of November SST anomalies (in ${ }^{\circ} \mathrm{C}$ ) averaged over 3 different regions: $60-30^{\circ} \mathrm{W}, 30-45^{\circ} \mathrm{N}, 60-40^{\circ} \mathrm{W}$, $40-45^{\circ} \mathrm{N}$, and $50-10^{\circ} \mathrm{W}, 40-55^{\circ} \mathrm{N}$. From (a) the Reynolds \& Smith (1994) (1981-2000) data and (b) the 1900-2000 analysis discussed above (the first years were removed due to poor data quality) and the UKMO GISST2.2 data set. Note that year 2000 is not shown in (b), and that the November 2000 spatial mean SST anomaly is $\sim 1.25^{\circ} \mathrm{C}$ higher than that in November 1999. Tick marks correspond to the beginning of the year

the $60-30^{\circ} \mathrm{W}, 30-45^{\circ} \mathrm{N}$ spatial mean SST from the met. no reconstruction with corresponding values from the HadISST1.1. The 2 curves tend to trace each other as well as the Reynolds data over their common interval, suggesting that the met. no reconstruction has captured most of the observed SST variations.

There are some cases in the period 1930-1960 when there were strongly positive SSTAs around Bermuda, but few such cases since 1960, apart from the November 2000 anomalies, which may be the strongest since 1871. The fact that the strongest anomalies coincide with the extreme November 2000 rainfall event in south-eastern Scandinavia is consistent with the rainfall event being related to the SSTs.

Further indications of the North Atlantic SSTAs' influence on the rainfall is found when the asymmetry of the SSTAs is considered. We compute the fractional area of prominent SSTAs (magnitudes greater than $0.5^{\circ} \mathrm{C}$ ) exceeding $10 \%$ of the western-central North Atlantic Ocean (WC basin: $80-45^{\circ} \mathrm{W}$, $30-55^{\circ} \mathrm{N}$ ) and the full width of the North Atlantic Ocean (FW: $80-10^{\circ} \mathrm{W}, 30-55^{\circ} \mathrm{N}$ ) respectively. Then, we compute a North Atlantic Asymmetry index (NAA index) describing the ratio of the WC basin's fractional area of anomalies to the corresponding area for the FW domain. Thus, an NAA index significantly larger than 1 is indicative of an asymmetric SSTA which is found predominately in the WC basin, and an index value that is significantly smaller than 1 corresponds to an anomaly in the eastern basin. A ratio of 1 indicates a symmetric anomaly. The results for the November months' NAA index are presented in Table 4 both for prominent warm anomalies (SSTAs $>0.5^{\circ} \mathrm{C}$ ) and cold anomalies (SSTAs $<-0.5^{\circ} \mathrm{C}$ ). The November months in question have been subdivided into months with high rainfall at Bjørnholt (as seen in the leftmost column in Table 3), normal rainfall, and dry months.

We find that a warm anomaly in the WC basin enhances the probability of large amounts of rain at Bjørnholt. On the other hand, if the warm pool is in the eastern basin, the likelihood of large amounts of rain is low. A cold pool to the east enhances the probability of large amounts of rain, whereas a cold anomaly in the WC basin reduces this probability. A bootstrap test was used to test the significance of the entries in Table 4, selecting at random 10000 different subsets of corresponding number of years as indicated in Table 4, Column 2.

The results from the stepwise regression ${ }^{2}$ applied to the 1900-2000 met. no SSTs and the November rainfall amount at Bjørnholt are shown in Fig. 5. There is a clear indication that the model is able to reproduce part of the rainfall in the Oslo region. The F-statistics are high for SST, and the p-values indicate extremely high confidence. The (adjusted) $\mathrm{R}^{2}$ value of 0.46 (the

\footnotetext{
${ }^{2}$ Carried out using the R-functions $\mathrm{lm}$ and step that perform backward-forward search, these functions are described in the R manuals. The stepwise regression aims to minimize the Akaike information criterion (AIC) (Wilks 1995)
} 
unadjusted $\mathrm{R}^{2}$ is 0.54 ) indicates that around $46 \%$ of the interannual variations in the November rainfall may be related to the SSTAs. The SSTs can account for $322 \mathrm{~mm}$ of the $564 \mathrm{~mm}$ received in November 2000. Similar regression analysis for September $\left(R^{2}=0.23\right.$, p-value $=$ $\left.1 \times 10^{-4}\right)$, October $\left(\mathrm{R}^{2}=0.27, \mathrm{p}\right.$-value $\left.=1 \times 10^{-4}\right)$, and December $\left(R^{2}=0.28\right.$, $p$-value $\left.=1 \times 10^{-6}\right)$ gave indications of relationships statistically significant at the $5 \%$ level (Table 5). The regression patterns for these

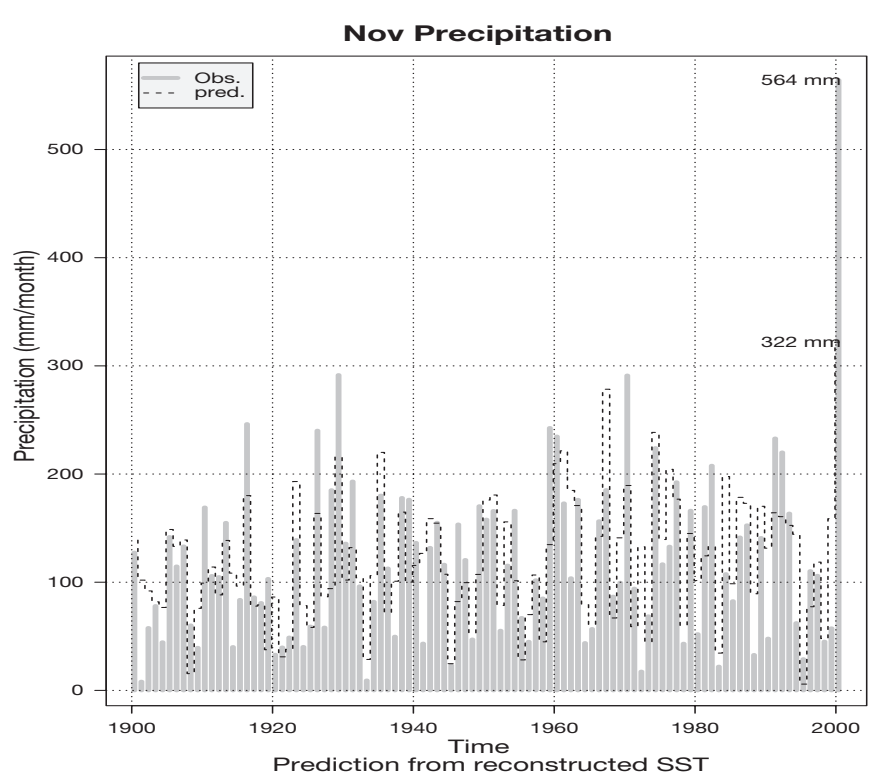

Fig. 5. Observed November rainfall amount in Oslo (grey) and predictions based on a regressional model using SST as inputs (dashed). $\mathrm{R}^{2}$ is 0.46

T-test on SLP PC associated with wet November

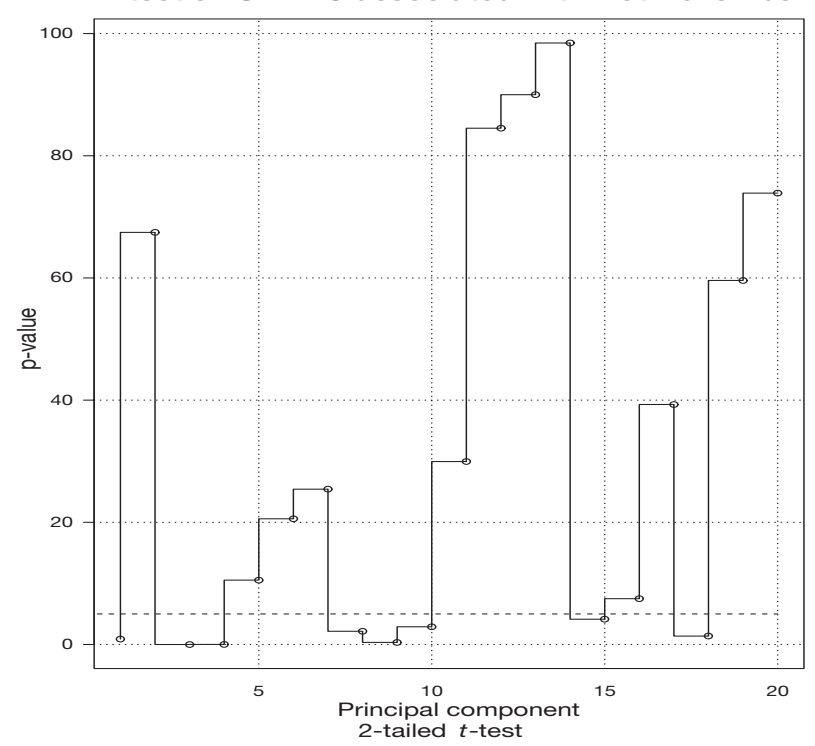

Fig. 6. Welch 2-sample $t$-test scores using SLP for 2 populations of PC values corresponding to wet and dry Novembers
Table 4. Number of November months when the area of SSTA magnitudes larger than $0.5^{\circ} \mathrm{C}$ in the North Atlantic exceed $10 \%$ of the entire domain. The results are categorized numbers of November months with warm and cold SSTAs respectively. Column 2 (n) lists the number of November months in each category that are 'wet' (at Bjørnholt, years listen in Column 2 in Table 3), 'normal' (months when $r r$ is within \pm 0.42 SD of the normal), and 'dry' (months when $r r<\mu-0.42 s$ ). The numbered categories reflect the asymmetry of the anomalies and are the number of cases where the NAA index values $<0.8$ (I), NAA $\in$ $[0.8,1.2]$ (II), or NAA > 1.2 (III). ${ }^{* *}$ Outside the $99 \%$ confidence interval or same value as the confidence limit (estimating using a bootstrap method with 10000 simulations); ${ }^{*}$ entries refer to outside $95 \%$ confidence interval

\begin{tabular}{|lcccc|}
\hline & $\mathrm{n}$ & $\mathrm{I}$ & $\mathrm{II}$ & $\mathrm{III}$ \\
\hline High SST & & & & \\
Wet & 33 & $0^{* *}$ & 4 & $10^{*}$ \\
Normal & 29 & 5 & 4 & 5 \\
Dry & 39 & $9^{*}$ & 5 & $2^{*}$ \\
Low SST & & & & \\
Wet & 33 & $11^{* *}$ & 4 & $0^{* *}$ \\
Normal & 29 & 4 & 6 & $1^{*}$ \\
Dry & 39 & $2^{*}$ & 2 & $15^{* *}$ \\
\hline
\end{tabular}

months were also similar to that of November, and $t$-tests similar to those in Fig. 2 suggested statistically significant EOFs. Hence, the relationship is not only valid for the November months.

The analysis was repeated, but with EOFs computed using the met. no SSTs from $30^{\circ} \mathrm{W}-40^{\circ} \mathrm{E}, 50-70^{\circ} \mathrm{N}$, and 7 of the EOFs from the smaller region could be associated with wet and dry Novembers according to the $t$-test (not shown). ${ }^{3}$ The ANOVA results shown in Table 5 indicate with a high degree of confidence that the regression fit is not likely due to chance. About $46 \%$ of the November rainfall variations can be attributed to the SSTs in the $30^{\circ} \mathrm{W}-40^{\circ} \mathrm{E}, 50-70^{\circ} \mathrm{N}$ region, and $323 \mathrm{~mm}$ of the $564 \mathrm{~mm}$ received in November 2000 could be accounted for by the SST.

Similar analysis to those for the met. no SST reconstruction, but using the HadISST1.1 SSTs, confirmed the statistically significant (at the $1 \%$ level) association between SSTs in the North Atlantic and the November rainfall around Oslo over the period 1871-1999. The ANOVA scores for these tests are summarized in Table 5. The results appear to be robust, as the repeated analysis with different settings give the same qualitative picture. The analyses point to a clear association between the rainfall and the North Atlantic and North Atlantic SST pattern in November. The regression analysis was then repeated for SST residuals $\left(\mathrm{SST}_{\text {res }}\right)$ where the linear SLP signal in the SST $\left(\mathrm{SS \hat {T }}=\beta_{1} \mathrm{SLP}\right)$ had been

\footnotetext{
${ }^{3}$ The exact number of significant EOFs does not necessarily have any importance, as long as some of the leading modes are related to the rainfall
} 
Table 5. ANOVA scores for linear stepwise regression models for monthly mean precipitation developed on SST or SLP. The adjusted $\mathrm{R}^{2}$ is based on the ordinary $\mathrm{R}^{2}$ statistic, but is 'adjusted' to penalise for higher $\mathrm{p}$-values. The residual SSTs were obtained by subtracting the best-fit SST $=\beta_{1}$ SLP based on SLP from the original SST. Similarly, SLP residuals $=$ SLP $-\beta_{2}$ SST. The 3 last rows show the ANOVA statistics where the original precipitation record has been replaced by residuals from a regression of the NAO index onto precipitation

\begin{tabular}{|c|c|c|c|c|c|}
\hline Element & Month & df & $F$ & $\mathrm{p}$-value & $\mathrm{R}^{2}$ \\
\hline $\operatorname{SST}\left(90^{\circ} \mathrm{W}-40^{\circ} \mathrm{E}, 40-75^{\circ} \mathrm{N}\right) \mathrm{rr}$ & Sep & 10,90 & 4.1 & $1 \times 10^{-4}$ & 0.23 \\
\hline $\operatorname{SST}\left(90^{\circ} \mathrm{W}-40^{\circ} \mathrm{E}, 40-75^{\circ} \mathrm{N}\right) \mathrm{rr}$ & Oct & 15,85 & 3.5 & $1 \times 10^{-4}$ & 0.27 \\
\hline $\mathrm{SST}\left(90^{\circ} \mathrm{W}-40^{\circ} \mathrm{E}, 40-75^{\circ} \mathrm{N}\right) \mathrm{rr}$ & Nov & 15,85 & 6.6 & $4 \times 10^{-9}$ & 0.46 \\
\hline $\operatorname{SST}\left(90^{\circ} \mathrm{W}-40^{\circ} \mathrm{E}, 40-75^{\circ} \mathrm{N}\right) r r^{\mathrm{a}}$ & Nov & 6,93 & 13.8 & $3 \times 10^{-11}$ & 0.44 \\
\hline $\mathrm{SST}\left(90^{\circ} \mathrm{W}-40^{\circ} \mathrm{E}, 40-75^{\circ} \mathrm{N}\right) r r$ & Dec & 6,94 & 7.4 & $2 \times 10^{-6}$ & 0.28 \\
\hline $\operatorname{SST}\left(30^{\circ} \mathrm{W}-40^{\circ} \mathrm{E}, 50-75^{\circ} \mathrm{N}\right) \mathrm{rr}$ & Nov & 16,84 & 7.6 & $7 \times 10^{-10}$ & 0.46 \\
\hline $\operatorname{SST}\left(90^{\circ} \mathrm{W}-40^{\circ} \mathrm{E}, 40-75^{\circ} \mathrm{N}\right) \log (r r)$ & Nov & 16,84 & 5.2 & $2 \times 10^{-7}$ & 0.40 \\
\hline $\operatorname{SST}\left(90^{\circ} \mathrm{W}-40^{\circ} \mathrm{E}, 40-75^{\circ} \mathrm{N}\right) r r^{0.2}$ & Nov & 11,89 & 7.9 & $2 \times 10^{-9}$ & 0.43 \\
\hline HadISST1.1 $\left(90^{\circ} \mathrm{W}-40^{\circ} \mathrm{E}, 40-75^{\circ} \mathrm{N}\right) \mathrm{rr}$ & Sep & 10,106 & 3.7 & $4 \times 10^{-4}$ & 0.19 \\
\hline HadISST1.1 $\left(90^{\circ} \mathrm{W}-40^{\circ} \mathrm{E}, 40-75^{\circ} \mathrm{N}\right) \mathrm{rr}$ & Oct & 8,108 & 4.8 & $5 \times 10^{-5}$ & 0.21 \\
\hline HadISST1.1 $\left(90^{\circ} \mathrm{W}-40^{\circ} \mathrm{E}, 40-75^{\circ} \mathrm{N}\right) \mathrm{rr}$ & Nov & 3,113 & 16.1 & $9 \times 10^{-9}$ & 0.28 \\
\hline HadISST1.1 $\left(90^{\circ} \mathrm{W}-40^{\circ} \mathrm{E}, 40-75^{\circ} \mathrm{N}\right) \mathrm{rr}$ & Dec & 9,107 & 4.2 & $1 \times 10^{-4}$ & 0.20 \\
\hline HadISST1.1 $\left(20^{\circ} \mathrm{W}-40^{\circ} \mathrm{E}, 50-75^{\circ} \mathrm{N}\right) \mathrm{rr}$ & Nov & 6,110 & 7.5 & $8 \times 10^{-7}$ & 0.25 \\
\hline HadISST1.1 $\left(0^{\circ} \mathrm{E}-30^{\circ} \mathrm{W}, 55-75^{\circ} \mathrm{N}\right) \mathrm{rr}$ & Nov & 6,110 & 6.6 & $6 \times 10^{-6}$ & 0.22 \\
\hline HadISST1.1 $\left(90^{\circ} \mathrm{W}-40^{\circ} \mathrm{E}, 40-75^{\circ} \mathrm{N}\right) r r^{0.2}$ & Nov & 5,111 & 9.8 & $9 \times 10^{-8}$ & 0.27 \\
\hline HadISST1.1 $\left(20^{\circ} \mathrm{W}-40^{\circ} \mathrm{E}, 50-75^{\circ} \mathrm{N}\right) \mathrm{rr} \mathrm{r}^{0.2}$ & Nov & 8,108 & 6.1 & $2 \times 10^{-6}$ & 0.26 \\
\hline HadISST1.1 $\left(0^{\circ} \mathrm{E}-30^{\circ} \mathrm{W}, 55-75^{\circ} \mathrm{N}\right) r r^{0.2}$ & Nov & 6,110 & 6.5 & $7 \times 10^{-6}$ & 0.22 \\
\hline $\operatorname{SLP}\left(90^{\circ} \mathrm{W}-40^{\circ} \mathrm{E}, 40-75^{\circ} \mathrm{N}\right) \mathrm{rr}$ & Nov & 8,92 & 20.5 & $1 \times 10^{-16}$ & 0.57 \\
\hline $\operatorname{SLP}\left(90^{\circ} \mathrm{W}-40^{\circ} \mathrm{E}, 40-75^{\circ} \mathrm{N}\right) \log (r r)$ & Nov & 10,90 & 18.5 & 0 & 0.61 \\
\hline $\operatorname{SLP}\left(90^{\circ} \mathrm{W}-40^{\circ} \mathrm{E}, 40-75^{\circ} \mathrm{N}\right) r r^{0.2}$ & Nov & 10,90 & 18.5 & 0 & 0.64 \\
\hline $\operatorname{SLP}\left(90^{\circ} \mathrm{W}-40^{\circ} \mathrm{E}, 40-75^{\circ} \mathrm{N}\right) r r^{2}$ & Nov & 9,91 & 7.3 & $6 \times 10^{-8}$ & 0.36 \\
\hline $\operatorname{SLP}\left(90^{\circ} \mathrm{W}-40^{\circ} \mathrm{E}, 40-75^{\circ} \mathrm{N}\right) r r^{1.5}$ & Nov & 10,90 & 10.0 & $4 \times 10^{-11}$ & 0.47 \\
\hline $\mathrm{SST}$ residual $\left(90^{\circ} \mathrm{W}-40^{\circ} \mathrm{E}, 40-75^{\circ} \mathrm{N}\right) \mathrm{rr}$ & Nov & 20,80 & 0.6 & 0.91 & -0.09 \\
\hline HadISST1. 1 res. $\left(90^{\circ} \mathrm{W}-40^{\circ} \mathrm{E}, 40-75^{\circ} \mathrm{N}\right) r r$ & Nov & 20,79 & 0.4 & 0.99 & -0.15 \\
\hline SLP residual $\left(90^{\circ} \mathrm{W}-40^{\circ} \mathrm{E}, 40-75^{\circ} \mathrm{N}\right) \mathrm{rr}$ & Nov & 20,80 & 1.1 & 0.35 & 0.02 \\
\hline $\mathrm{SST}\left(90^{\circ} \mathrm{W}-40^{\circ} \mathrm{E}, 40-75^{\circ} \mathrm{N}\right) r r-\mathrm{NAOI}$ & Nov & 14,86 & 6.4 & $1 \times 10^{-8}$ & 0.43 \\
\hline HadISST1.1 $\left(90^{\circ} \mathrm{W}-40^{\circ} \mathrm{E}, 40-75^{\circ} \mathrm{N}\right) r r$-NAOI & Nov & 3,113 & 13.6 & $1 \times 10^{-7}$ & 0.25 \\
\hline $\operatorname{SLP}\left(90^{\circ} \mathrm{W}-40^{\circ} \mathrm{E}, 40-75^{\circ} \mathrm{N}\right) r r$-NAOI & Nov & 8,92 & 14.3 & $2 \times 10^{-13}$ & 0.52 \\
\hline $\mathrm{SST}\left(90^{\circ} \mathrm{W}-40^{\circ} \mathrm{E}, 40-75^{\circ} \mathrm{N}\right) r r$ & Sep-Oct & 3,97 & 4.71 & $4 \times 10^{-3}$ & 0.10 \\
\hline HadISST1.1 $\left(90^{\circ} \mathrm{W}-40^{\circ} \mathrm{E}, 40-75^{\circ} \mathrm{N}\right) r r$ & Sep-Oct & 7,109 & 3.75 & $1 \times 10^{-3}$ & 0.14 \\
\hline $\mathrm{SST}\left(90^{\circ} \mathrm{W}-40^{\circ} \mathrm{E}, 40-75^{\circ} \mathrm{N}\right)$ rr & Oct-Nov & 15,85 & 1.23 & 0.26 & 0.03 \\
\hline HadISST1.1 $\left(90^{\circ} \mathrm{W}-40^{\circ} \mathrm{E}, 40-75^{\circ} \mathrm{N}\right) r r$ & Oct-Nov & 8,108 & 1.76 & 0.09 & 0.05 \\
\hline $\operatorname{SST}\left(90^{\circ} \mathrm{W}-40^{\circ} \mathrm{E}, 40-75^{\circ} \mathrm{N}\right) r r$ & Nov-Dec & 9,91 & 2.34 & 0.02 & 0.11 \\
\hline HadISST1.1 $\left(90^{\circ} \mathrm{W}-40^{\circ} \mathrm{E}, 40-75^{\circ} \mathrm{N}\right) \mathrm{rr}$ & Nov-Dec & 13,103 & 2.21 & 0.01 & 0.12 \\
\hline $\operatorname{SLP}\left(90^{\circ} \mathrm{W}-40^{\circ} \mathrm{E}, 40-75^{\circ} \mathrm{N}\right) r r$ & Sep-Oct & 5,95 & 1.98 & 0.09 & 0.05 \\
\hline $\operatorname{SLP}\left(90^{\circ} \mathrm{W}-40^{\circ} \mathrm{E}, 40-75^{\circ} \mathrm{N}\right) r r$ & Oct-Nov & 6,94 & 5.19 & $1 \times 10^{-4}$ & 0.20 \\
\hline $\operatorname{SLP}\left(90^{\circ} \mathrm{W}-40^{\circ} \mathrm{E}, 40-75^{\circ} \mathrm{N}\right) r r$ & Nov-Dec & 8,92 & 3.78 & $7 \times 10^{-4}$ & 0.18 \\
\hline
\end{tabular}

removed prior to the analysis using a multivariate regression: $\mathrm{SST}_{\text {res }}=\mathrm{SST}-\mathrm{SST}$ (Table 5). The results from the SST residuals suggest that all the predictability ${ }^{4}$ in SST is related to SLP.

As a reference, the $t$-test and regression analysis was repeated using SLP instead of SST. The results suggest that the interannual variations in the November rainfall indeed are related to changes in the circulation as expected. The $t$-test results shown in Fig. 6 indicate that there are 8 spatial SLP modes that can be related to wet November months. The enhanced rainfall is associated with an anomalous southerly flow type bringing in moist air masses over southern Norway (Fig. 7). The predictions based on regression analysis, shown in Fig. 8, suggest that the SLP is highly correlated with the autumn rainfall over south-eastern Norway, but the SLP variations fail to account for the extreme events. In fact, the linear SLP-based model predicts a lower value (284 of $564 \mathrm{~mm}$ ) for November 2000 than does the SST-based model (322 mm).

\footnotetext{
${ }^{4}$ Here we use the term 'predict' when referring to model results in general, and this term may include forecast, nowcast, and hindcast. A model in this context may be a linear relationship between a single time series (predictand: $\hat{y}$ ) and a series of spatial fields of some quantity (predictor X): $\hat{y}=$ $b \mathrm{X}+c$. The concept predictability concerns the question of whether there is a signal in $\mathrm{X}$ that can account for variations in $\hat{y}$
} 


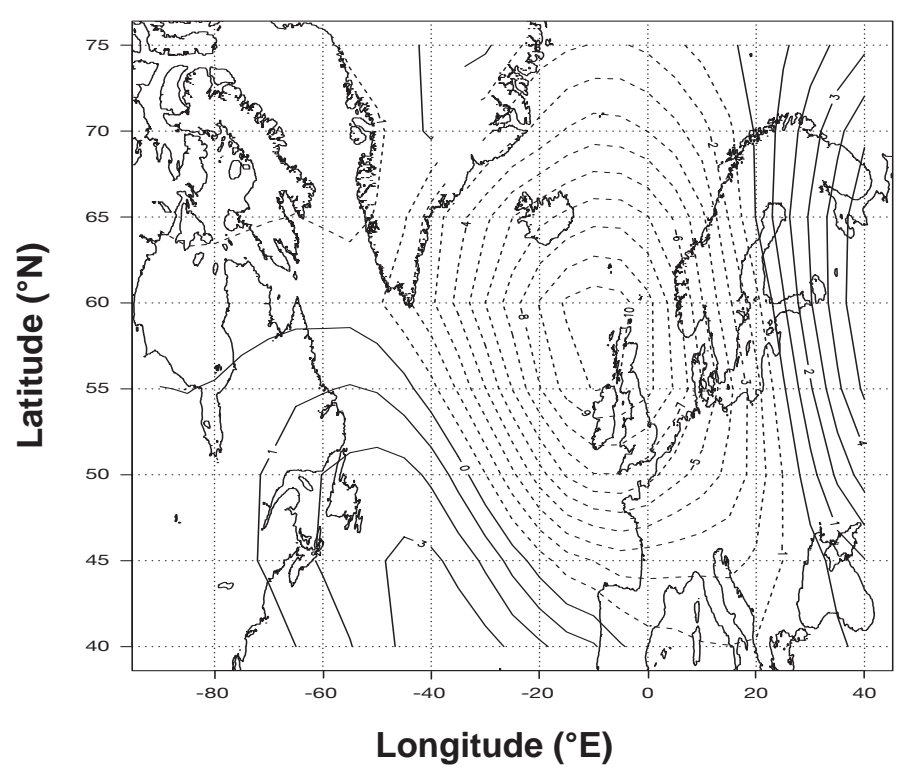

Fig. 7. The difference between composite of SLP for wet and dry Novembers. The contour intervals are $1 \mathrm{hPa}$

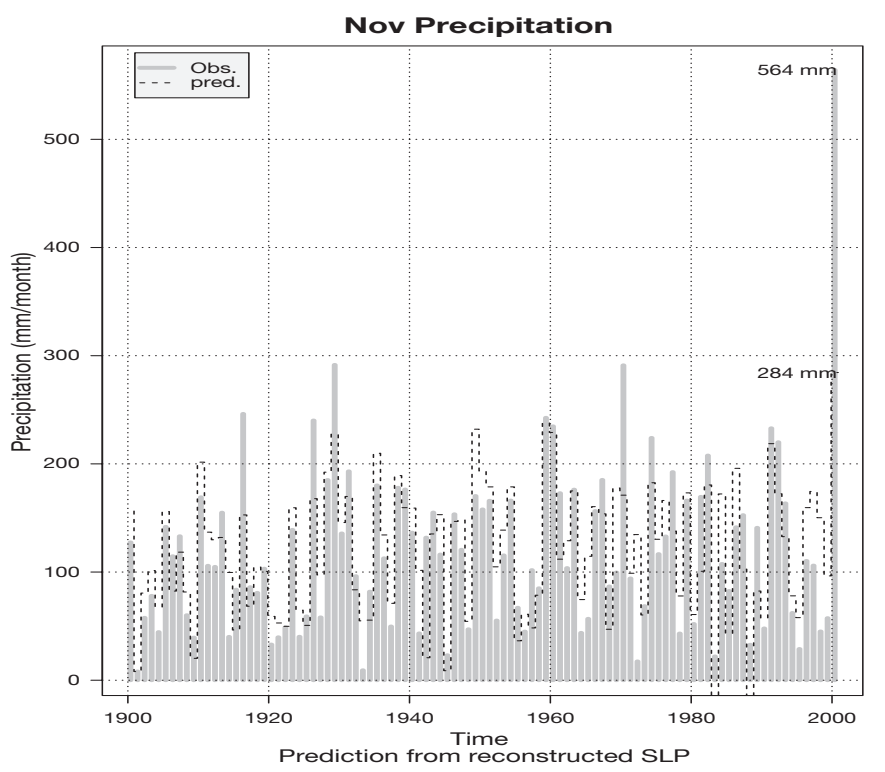

Fig. 8. The prediction of the rainfall using an SLP-based regression model. $R^{2}$ is 0.57

The ANOVA table (Table 5) shows that the results are all highly significant and that there is an overall stronger signal in the SLP than in the SST. It is likely that the circulation has a stronger effect on the rainfall, but the comparison between the ANOVA scores may also be affected by errors. The errors in the SLP are expected to be smaller than in the SST data, since SLP often is easier to measure and the spatial SLP struc-

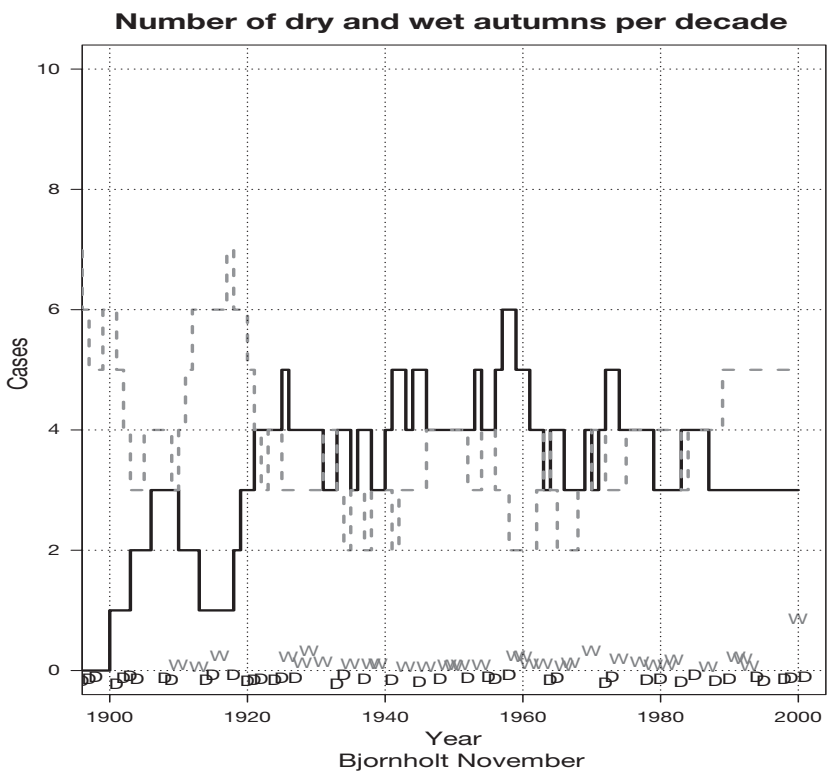

Fig. 9. The long-term trend in the number of wet (solid) and dry (dashed) Novembers per decade (running mean). The occurrence of the wet (W) and dry (D) events are also indicated at the bottom of the plot

tures tend to be more extensive than the spatial SST patterns. Table 5 also shows the results from a regression analysis on the rainfall and SLP residuals, obtained by removing the linear SST signal in the SLP. The high p-value and low F-statistics suggest that most of the predictability associated with the SLP also is related to SST variations. Hence, the Oslo rainfall appears to be related to a coupled SST-SLP mode, implying that SST is indeed important.

Lagged regression was also carried out between SST and the rainfall and between SLP and the rainfall (Table 5), and the results suggest that there may sometimes be a weak association between the SSTs and the following month's rainfall. However, the $\mathrm{R}^{2}$-values for the lagged regression are greater for SLP than for SST in 2 of the 3 autumn months.

An analysis involving a count of how many entries fall into each rainfall category, dry, normal and wet, may be used to identify long-term shifts in the rainfall statistics. This statistic is not as sensitive to outliers as the extremevalue analysis, and the results suggest that the highrainfall frequency over Bjørnholt has changed over the last century (Fig. 9) and there has been an increase in the frequency of wet Novembers. It appears from Fig. 9 that most of the change in the wet-November frequency took place before the 1930s. The 1960s was the decade with highest wet-November frequencies. The implications of this change may be that the extreme-value analysis referred to in Section 1 overestimates the future return period and that extreme rainfall events exceeding $564 \mathrm{~mm}$ will not be as rare as initially estimated. 


\section{DISCUSSION}

The analyses suggest that SSTs are related to the rainfall over south-eastern Norway, although atmospheric circulation patterns tend to be the most important factor accounting for interannual variations in the November rainfall over Oslo. Our results support the conclusion of Rodwell et al. (1999); it is especially interesting to note the association between the SSTAs in their Fig. 3a and the positive precipitation anomaly over southern Norway in their Fig. 3d, albeit for the winter season. The results of this analysis are consistent with 2 hypotheses: (1) the atmospheric circulation pattern produces both positive SSTAs in the northwestern Atlantic Ocean and more autumn rain over south-eastern Norway; (2) extensive and strong positive SSTAs in the northwestern Atlantic Ocean affect the atmospheric circulation pattern and influence the rainfall in south-eastern Norway. The SSTs may play an active role for the rainfall in either scenario, as high SSTs may lead to enhanced evaporation (Rodwell et al. 1999), and higher moisture levels available for precipitation thus reinforcing the rainfall. The analyses on the SST and SLP residuals suggest that neither SST nor SLP alone can account for the November rainfall variations in south-eastern Norway but that rainfall may be associated with a coupled SST-SLP pattern.

The SSTAs off Newfoundland tend to be anti-correlated with the sub-tropical SSTAs in the North Atlantic tri-pole pattern; Sutton et al. (2000) reported that these sub-tropical SSTs may produce an atmospheric response. They also suggest that the mid-latitude SSTAs may possibly affect the storm-generation processes or the storm track. One indication of the SSTs playing an active role is that the SST-based rainfall estimate for the extreme November 2000 event is higher than the corresponding SLP-based estimate.

Based on previous model studies and lag-correlation analysis (Frankignoul et al. 1998) giving high correlation values when the atmosphere leads the ocean, it has been argued that the atmosphere tends to drive the ocean in the mid-latitudes. The lag-correlation result may point to a linear response in the ocean, but does not rule out an important but non-linear atmospheric response to SSTAs or a response depending on the atmospheric state (Bjerknes 1959). Palmer (1993) has proposed that the most likely atmospheric response to a change in the diabatic heating, such as a SSTA, is a change in the population of weather regimes. Furthermore, additional factors such as imposed noise and different time scales in the atmosphere and ocean may affect the results from the lag-correlation. There is little doubt about a coupling between SST and SLP, but it is difficult to prove whether SST influences SLP most strongly or vice versa. The statistical analysis pre- sented here says little about causality, apart from hinting to an active role for the SST in terms of the southeastern Norwegian November mean rainfall. Some of the recent model studies suggest that the mid-latitude SST may influence the atmosphere. Although this issue is not yet resolved, our results support the hypothesis that the mid-latitude ocean is influencing the atmosphere.

The observations suggest that the SSTAs in parts of the North Atlantic were the highest ever recorded. These findings lead to the question of whether there is a connection between the warming trend associated with increased atmospheric $\mathrm{CO}_{2}$ concentrations and the extreme November rainfall amounts. If the extreme November rainfall is related to the warming trend, then one would expect a return period for such occurrences to be less than $\sim 600$ yr. On the other hand, the long-term shift in the number of wet Novembers shown in Fig. 9 is due to the increase in incidences between 1900 and 1940, but global warming is most pronounced since the 1960s (IPCC 2001), in which time there has been no significant trend in the number of wet Oslo autumns. Thus it is difficult to attribute a trend in the number of wet Novembers to an enhanced greenhouse effect.

Any relationship between SST and local rainfall is of great interest for climate analysis, seasonal forecasting and empirical downscaling of climate-change scenarios. The established link between the North Atlantic SSTs and precipitation over south-eastern Norway implies that in order for atmosphere-ocean general circulation models to give reasonable scenarios for extreme monthly rainfall, they must be able to reasonably predict the North Atlantic SST fields.

\section{CONCLUSIONS}

There is clear evidence suggesting that the November rainfall in south-eastern Scandinavia is connected with the SSTAs in the northwestern Atlantic along with a low-pressure system over the British Isles. Hence, a likely explanation for the wet November 2000 is the unusually warm SSTs off the North American east coast in addition to the persistent SLP pattern. The additional observation that the strongest SSTAs around Bermuda in at least 100 yr seem to coincide with record-breaking November rainfall around Oslo further suggests that this extreme event was related to the warm anomaly in the North Atlantic Ocean. The most important factor controlling the rainfall, however, is the SLP pattern responsible for the transport of moist air to south-eastern Norway.

There may have been a long-term shift in the frequency of wet-November events according to a trend 
analysis. If there is a real trend in the rainfall statistics, then the return period of Bjørnholt November rainfall exceeding $564 \mathrm{~mm}$ may indeed be less than $600 \mathrm{yr}$, as estimated using a Gumbel extreme value analysis.

Acknowledgements. This work was done under the Norwegian Regional Climate Development under Global Warming (RegClim) project and the Norwegian Ocean Climate (NOClim) project; it was supported by the Norwegian Research Council (Contracts NRC-No. 120656/720 and NRCNo. 139815/720) and the Norwegian Meteorological Institute. Jim Arnott of the Hadley Centre, UKMO, kindly provided SSTs from the HadISST1.1 analysis. The MODAS SSTs were kindly provided by Tamara L. Townsend at the Naval Research Laboratory in Stennis, MS, USA. We are also grateful for valuable advice from I. Hanssen-Bauer, Eirik J. Førland, Nils Gunnar Kvamstø, Tore Furevik. The analysis was carried out using the R (Gentleman \& Ihaka 2000, Ellner 2001) data processing and analysis language (http://cran.rproject.org/). The analysis was based on data stored in UCAR/Unidata's netCDF format and some of the figures are produced with NOAA-PMEL's tool Ferret (Hankin et al. 1992).

\section{LITERATURE CITED}

Benestad RE (1999) S-mode and T-mode EOFs from a GCM modeller's perspective: notes on the linear algebra. Klima 24/99. DNMI, Oslo

Benestad RE (2000) Analysis of gridded sea level pressure and 2-meter temperature for 1873-1998 based on UEA and NCEP re-analysis II. KLIMA 03/00. DNMI, Oslo

Bjerknes J (1959) Temperaturforandring i Golfströmmen i tidsrummet for klimaforbedringer i Norden. YMER, Stockholm

Busuioc A, Chen D, Hellström C (2001) Performance of statistical downscaling models in GCM validation and regional climate change estimates: application for Swedish precipitation. Int J Climatol 21:557-578

Coles S (1999) Extreme value theory and applications. In: Notes from a course on EVT and applications presented at the 44th Reunião Annual da RBRAS e 8th SEAGRO, at Bucato, São Paulo, Brazil, 26-30 July, 1999. Available at www.maths.lancs.ac.uk/coless

Colman A, Davey M (1999) Prediction of summer temperature, rainfall and pressure in Europe from preceding winter North Atlantic Ocean temperatures. Int J Climatol 19: 513-536

Drevillion M, Terray L, Rogel P, Cassou C (2001) Mid latitude Atlantic SST influences on European winter climate variability in the NCEP reanalysis. Clim Dyn 18:331-334

Ellner SP (2001) Review of R, Version 1.1.1. Bull Ecol Soc Am 82(2):127-128

Fox DN, Teague WJ, Barron CN, Carnes MR, Lee CM (2001) The Modular Ocean Data Assimilation System (MODAS). J Atmos Ocean Tech 19:240-252

Frankignoul C (1985) Sea surface temperature anomalies, planetary waves, and air-sea feedback in the mid latitudes. Rev Geophys 23(4):357-390

Frankignoul C, Czaja A, L'Heveder B (1998) Air-sea feedback in the North Atlantic and surface boundary conditions for ocean models. J Clim 11:2310-2324

Gentleman R, Ihaka R (2000) Lexical scope and statistical computing. J Comput Graph Stat 9:491-508

Hankin S, Davison J, O'Brien K, Harrison DE (1992) FERRET: a computer visualization and analysis tool for gridded data. Data report ERL PMEL-38. NOAA, Seattle

Hanssen-Bauer I, Førland E (2000) Temperature and precipitation variations in Norway 1900-1994 and their links to atmospheric circulation. Int J Climatol 20:1693-1708

Higuchi K, Huang J, Shabbar A (1999) A wavelet characterization of the North Atlantic oscillation variation and its relationship to the North Atlantic sea surface temperature. Int J Climatol 19:1119-1129

IPCC (2001) IPCC WGI Third Assessment Report. Summary for policymakers. WMO, Geneva

Johansson Å, Barnston A, Saha S, van den Dool H (1998) On the level and origin of seasonal forecast skill in Northern Europe. J Atmos Sci 55:103-127

Kalnay E, Kanamitsu M, Kistler R, Collins W, Deaven D and 17 others (1996) The NCEP/NCAR 40-Year Reanalysis Project. Bull Am Meteorol Soc 77(3):437-471

Kaplan A, Cane MA, Kushnir Y, Clement AC, Blumenthal MB, Rajagopalan B (1998) Analyses of global sea surface temperature 1856-1991. J Geophys Res 103(C9): 18567-18589

Kushnir Y, Held IM (1996) Equilibrium atmospheric response to North Atlantic SST anomalies. J Clim 9:1208-1220

Lau NC (1985) Modeling the seasonal dependence of the atmospheric response to El Niños in 1962-76. Mon Weather Rev 113:1970-1996

Lau NC (1996) Interactions between global SST anomalies and the midlatitude atmospheric circulation. Bull Am Meteorol Soc 78(1):21-33

Lorenz EN (1956) Empirical orthogonal functions and statistical weather prediction. Sci Rep 1. Department of Meteorology, MIT, Cambridge, MA

Marsh TJ (2001) The 2000/1 floods in the UK-a brief overview. Weather 56:343-345

North GR, Bell TL, Cahalan RF (1982) Sampling errors in the estimation of empirical orthogonal functions. Mon Weather Rev 110:699-706

Palmer TN (1993) A nonlinear dynamical perspective on climate change. Weather 48:313-348

Palmer TN, Sun ZB (1985) A modelling and observational study of the relationship between sea surface temperature in the north-west Atlantic and the atmospheric general circulation. Q J R Meteorol Soc 111:947-975

Parker DE, Jackson M, Horton EB (1995) The 1961-1990 GISST2.2 sea surface temperature and sea-ice climatology. Clim Res Tech Note 63. Hadley Centre, UK Meteorological Office, Bracknell

Reynolds RW, Smith TM (1994) Improved global sea surface temperature analysis using optimum interpolation. J Clim 7:929-948

Rîmbu N, Le Treut H, Janicot S, Boroneant C, Laurent C (2001) Decadal precipitation variability over Europe and its relation with surface atmospheric circulation and sea surface temperature. Q J R Meteorol Soc 127(572):315-330

Robertson AW, Mechoso CR, Kim YJ (2000) The influence of Atlantic surface temperature anomalies on the North Atlantic Oscillation. J Clim 13:122-138

Rodwell MJ, Rowell DP, Folland CK (1999) Oceanic forcing of the wintertime North Atlantic Oscillation and European climate. Nature 398:320-323

Selten FM, Haarsma RJ, Opsteegh JD (1999) On the mechanism of the North Atlantic decadal variability. J Clim 12: 1956-1973

Skeie P, Kvamstø NG (2000) Atmospheric response to variations in the Labrador Sea ice-cover as indicated by ensemble simulations with ARPEGE. In: Iversen T, Høiskar BAK (eds) RegClim. General Technical report, no. 4, NILU, Kjeller, p 135-138. Available at www.nilu.no/regclim/ 
Slutz RJ, Lubker SJ, Hiscox JD, Woodruff SD, Jenne RL, Steurer PM, Elms JD (1985) Comprehensive OceanAtmosphere Data Set; Release 1. Tech Rep, Climate Research Program, Boulder, CO

Sutton RT, Norton WA, Jewson SP (2000) The North Atlantic Oscillation-What role for the ocean? Atmos Sci Lett (available at: http://www.academicpress.com/asl)

Editorial responsibility: Hans von Storch, Geesthacht, Germany
Timmermann A, Latif M, Voss R, Grötzner A (1998) Northern hemispheric interdecadal variability: a coupled air-sea mode. J Clim 11:1906-1931

von Storch H, Zwiers FW (1999) Statistical analysis in climate research. Cambridge University Press, Cambridge

Wilks DS (1995) Statistical methods in the atmospheric sciences. Academic Press, Orlando

Submitted: February 8, 2002; Accepted: July 23, 2002

Proofs received from author(s): December 12, 2002 